RANDOMISED CONTROLLED TRIAL

\title{
Cyclosporin A monotherapy versus cyclosporin A and methotrexate combination therapy in patients with early rheumatoid arthritis: a double blind randomised placebo controlled trial
}

\author{
A H Gerards, R B M Landewé, A P A Prins, G A W Bruijn, H S Goei Thè, R F J M Laan, \\ B A C Dijkmans
}

See end of article for authors' affiliations

Correspondence to:

Correspondence to:
Dr A H Gerards, Vlietland ziekenhuis, lokatie

Schiedam, Burg

Knappertlaan 25, 3116

BA Schiedam, The

Netherlands;

agerards@SSVZ.nl

Accepted

22 November 2002

\begin{abstract}
Objective: To compare the efficacy and toxicity of cyclosporin A (CsA) monotherapy with CsA plus methotrexate (MTX) combination therapy in patients with early rheumatoid arthritis (RA).

Patients and methods: 120 patients with active RA, rheumatoid factor positive and/or erosive, were randomly allocated to receive CsA with MTX $(n=60)$ or CsA with placebo $(n=60)$. Treatment with CsA was started in all patients at $2.5 \mathrm{mg} / \mathrm{kg} /$ day and increased to a maximum of $5 \mathrm{mg} / \mathrm{kg} / \mathrm{day}$ in 16 weeks. MTX was started at $7.5 \mathrm{mg} /$ week and increased to a maximal dose of $15 \mathrm{mg} /$ week at week 16. Primary outcomes were clinical remission (Pinals criteria) and radiological damage (Larsen score), at week 48 .

Results: Treatment was discontinued prematurely in 27 patients in the monotherapy group (21 because of inefficacy, and six because of toxicity) and in 26 patients in the combination therapy group (14 and 12, respectively). At week 48, clinical remission was achieved in four patients in the monotherapy group and in six patients in the combination therapy group $(p=0.5)$. The median Larsen score increased to $10(25$ th, 75 th centiles: $3.5 ; 13.3)$ points in the monotherapy group and to $4(1.0 ; 10.5)$ points in the combination therapy group $(p=0.004) .28 / 60(47 \%)$ of patients in the monotherapy group $\vee 34 / 60(57 \%)$ of patients in the combination therapy group had reached an American college of Rheumatology $20 \%$ (ACR20) response $(p=0.36)$ at week $48 ; 15 / 60(25 \%) \vee 29 / 60(48 \%)$ of patients had reached an ACR50 response $(p=0.013)$; and $7(12 \%) \vee 12(20 \%)$ of patients had reached an $A C R 70$ response $(p=0.11)$. Their was a tendency towards more toxicity in the combination therapy group.

Conclusions: In patients with early RA, neither CsA plus MTX combination therapy nor CsA monotherapy is very effective in inducing clinical remission. Combination therapy is probably better at improving clinical disease activity, and definitely better at slowing radiological progression. Combination therapy should still be compared with methotrexate monotherapy.
\end{abstract}

B oth early diagnosis and early treatment with disease modifying antirheumatic drugs (DMARDs) are important in patients with rheumatoid arthritis (RA) to inhibit radiological progression and to prevent long term functional loss. ${ }^{1-9}$ Methotrexate (MTX) is considered one of the most powerful conventional DMARDs which may retard radiological progression, ${ }^{10-14}$ and has an acceptable toxicity spectrum. ${ }^{14-16}$ These characteristics make MTX the anchor drug in the treatment of RA, and in a number of studies in early RA MTX was used as one part of a DMARD combination. ${ }^{15-18}$ Cyclosporin A (CsA) has proved to be effective in both advanced and early RA..$^{18-25}$ The toxicity, which is particularly increased in the presence of serum creatinine and hypertension, is considered manageable if dosage guidelines are strictly maintained. $.^{20} 26-28$ In a number of studies it has been suggested that radiological progression is retarded by CsA in comparison with placebo or other DMARDs. ${ }^{29-31}$

Because both drugs have different mechanisms of action, and their toxicity patterns do not overlap, the combination of MTX with CsA may offer complementary efficacy. ${ }^{32}$ Patients with advanced RA and a poor response to MTX have shown significant clinical improvement after the addition of CsA, ${ }^{18}$ and the drug combination was tolerated well. These results were a basis for investigating the potential of CsA in combination with MTX in achieving clinical remission and in slowing radiological progression in patients with early RA. We proposed the hypothesis that patients with early RA and factors indicating a poor prognosis ${ }^{8}$ would gain most from early aggressive intervention by combination therapy

The purpose of this study was to investigate whether the combination of MTX and CsA is more effective than CsA monotherapy in inducing clinical remission and slowing radiological progression in patients with early RA

\section{PATIENTS AND METHODS}

The study was conducted in 16 centres throughout the Netherlands between November 1996 and November 1999. Patients were eligible for the study if they met the following inclusion criteria: RA according to the 1987 American Rheumatism Association criteria, ${ }^{33}$ age between 18 and 70 years, and a disease duration of less than three years. Patients had to have factors indicating a poor prognosis, defined as at least one

Abbreviations: ACR, American College of Rheumatology; ALT, alanine aminotransferase; $A S T$, aspartate aminotransferase; CRP, $C$ reactive protein; $\mathrm{CsA}$, cyclosporin $\mathrm{A}$; DMARDs, disease modifying antirheumatic drugs; ESR, erythrocyte sedimentation rate; MTX, methotrexate; RA, rheumatoid arthritis; RCT, randomised controlled trial; VAS, visual analogue scale 
Table 1 Patient characteristics at baseline. A 48 week placebo controlled trial comparing cyclosporin $\mathrm{A}(\mathrm{Cs} \mathrm{A})$ monotherapy with CsA and methotrexate (MTX) combination therapy in patients with RA with poor prognosis

\begin{tabular}{lll}
\hline Characteristic & CsA plus MTX $(n=60)$ & CsA (n=60) \\
\hline Age (years) & $52.5(10.6)^{*}$ & $51.2(11.6)^{*}$ \\
Disease duration (months) & $2.9(3.5)^{*}$ & $2.7(5.7)^{*}$ \\
Women & $37(62) \dagger$ & $42(70) \dagger$ \\
Erosive at start of study & $32(53) \dagger$ & $27(45) \dagger$ \\
Rheumatoid factor positive at start & $56(93) \dagger$ & $58(97) \dagger$ \\
DMARD used before study (patients) & $11(18) \dagger$ & $6(10) \dagger$ \\
\hline \multirow{2}{*}{ *Mean (standard deviation); †Number of patients (percentage). }
\end{tabular}

Table 2 Total number adverse events related to study drug

\begin{tabular}{lcc}
\hline & Group & \\
\cline { 2 - 3 } Kind of adverse event & CsA plus MTX & CsA \\
\hline A period with $>30 \%$ raised serum creatinine & 47 & 42 \\
A period with hypertension & 38 & 38 \\
Gastric intestinal complaints & 28 & 26 \\
Hypertrichosis & 13 & 19 \\
Headache & 11 & 13 \\
Raised serum potassium & 10 & 4 \\
Liver enzyme disturbances & 7 & 7 \\
Paraesthesias & 6 & 7 \\
Gingivitis & 5 & 8 \\
Fluid retention & 5 & 3 \\
Tremor & 4 & 2 \\
Metrorrhagia & 3 & 1 \\
Fatigue & 1 & 3 \\
Others & 19 & 19 \\
Total & & 192 \\
\hline
\end{tabular}

erosive lesion and/or a positive serum rheumatoid factor test (Latex test, and/or Rose-Waaler test, and/or IgM rheumatoid factor enzyme linked immunosorbent assay (ELISA)). Patients had to have active disease, defined as at least three out of four activity criteria: six swollen joints (out of 66); six tender joints (out of 68); an erythrocyte sedimentation rate (ESR) of at least $28 \mathrm{~mm} / \mathrm{lst} \mathrm{h}$, and/or a C reactive protein (CRP) of at least $20 \mathrm{mg} / \mathrm{l}$; a global assessor's score of disease activity (ranging from $\mathrm{l}=$ no activity to $5=$ severe activity) of at least 4 . Only patients with a normal renal function (a creatinine clearance as calculated by the Cockroft formula ${ }^{34}$ of at least 80 $\mathrm{ml} / \mathrm{min}$ for men and of at least $70 \mathrm{ml} / \mathrm{min}$ for women) were allowed to enter the study.

Patients were excluded from the study if they had received previous treatment with CsA or MTX or more than one other DMARD, and if treatment with any DMARD had been for longer than three months. Other exclusion criteria were a white blood cell count of $\leqslant 3 \times 10^{9} / 1$; platelets of $\leqslant 100 \times 10^{9} /$; serum aspartate aminotransferase (AST), serum alanine aminotransferase (ALT), or bilirubin levels exceeding twice the upper limit of normal; a systolic blood pressure of $\geqslant 160$ $\mathrm{mm} \mathrm{Hg}$ and a diastolic blood pressure $\geqslant 90 \mathrm{~mm} \mathrm{Hg}$; a history of hypertension (treated or untreated) or malignancy or epilepsy; the presence of a chronic infection or gastric duodenal disease; and the use of drugs with a known interaction with CsA or with MTX.

Oral corticosteroids were not permitted and non-steroidal anti-inflammatory drugs were only permitted if the dose was stable during the two weeks before randomisation. Intraarticular injections were allowed during the study. For a period of four weeks injected joints were counted as swollen and tender.

\section{Study design and monitoring}

The study protocol was approved by the medical ethics committees of the participating hospitals and all patients gave written informed consent.

After providing informed consent and after a four week screening period, patients were randomly assigned to one of the two study arms. Randomisation was performed by a computer generated list. Patients received the study drug for a maximum of 48 weeks.

In one study arm CsA was combined with MTX (combination therapy group) and in the other arm CsA was combined with a placebo (monotherapy group). Folic acid $1 \mathrm{mg} /$ day was prescribed to all patients. CsA was provided by the patient's regular pharmacist on prescription. The placebo was produced by the pharmacy of the VU Medical Centre and was packed and made indistinguishable from MTX at that centre. CsA was started at a dose of $2.5 \mathrm{mg} / \mathrm{kg} / \mathrm{day}$, and was increased in three steps to a maximum of $5 \mathrm{mg} / \mathrm{kg} /$ day during the first 16 weeks. A period of at least four weeks between two CsA dose increments was required. MTX or placebo was started at a dose of 7.5 $\mathrm{mg} /$ week, which was kept constant during the first 16 weeks of the study and was increased to $15 \mathrm{mg} /$ week at week 16 .

The CsA and/or MTX (placebo) study drug dosage was only increased if the patient did not meet the Pinals criteria for clinical remission, and if safety guidelines for dosing CsA and MTX were met. ${ }^{28}$

At each visit (every two weeks during the first 12 weeks; every four weeks thereafter) blood pressure was measured, laboratory safety tests (biochemistry and haematology) were performed, and side effects were monitored.

The CsA dosage was decreased by $50 \mathrm{mg} /$ day if the serum creatinine level had increased by more than $30 \%$ from baseline at two consecutive visits and/or if blood pressure exceeded 


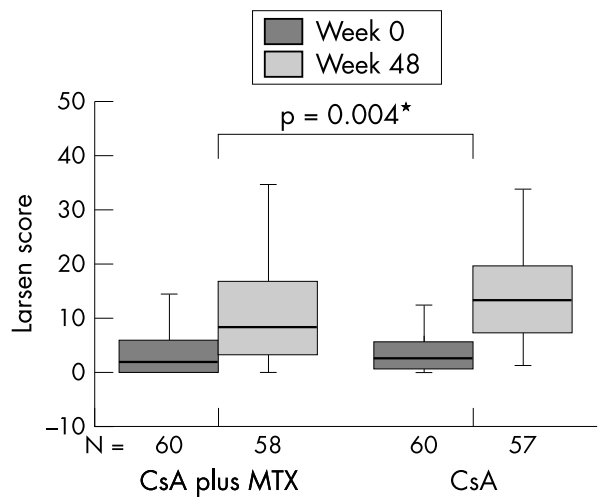

Figure 1 Radiological progression. Median Larsen scores (25th, 75th centiles) at baseline and after 48 weeks of treatment are given in each group. The $p$ value refers to the between-group difference in change after 48 weeks. Numbers are the number of patients on which the analyses were based.

160/95 mm Hg at two consecutive visits. Treatment with a calcium blocking agent to lower blood pressure without CsA dose reduction was allowed.

The MTX dosage was decreased by $7.5 \mathrm{mg}$ if leucopenia $\left(\leqslant 3 \times 10^{9} / 1\right)$ or thrombocytopenia $\left(\leqslant 100 \times 10^{9} / 1\right)$ developed or if there was an increase of ALT or AST by more than twice the upper limit at two consecutive visits.

\section{End points}

The primary end points were clinical remission according to the Pinals criteria ${ }^{35}$ with a minor modification, ${ }^{35}$ and radiological damage according to the Larsen modified Larsen score. ${ }^{36}$ Both primary end points were assessed at week 48. In brief, patients were considered to be in clinical remission if they met five of the six following criteria: duration of morning stiffness not exceeding 15 minutes; no fatigue; no joint pain (by history); no joint tenderness or pain on motion; no soft tissue swelling in joints or tendon sheaths; ESR $<30 \mathrm{~mm} / \mathrm{lst} \mathrm{h}$ (female) or $<20 \mathrm{~mm} / \mathrm{lst}$ h (male)/or a CRP $<10 \mathrm{mg} / \mathrm{l}$. An $x$ ray examination was made at baseline and after 48 weeks, and $x$ rays were scored by two observers unaware of the study drug, but aware of the chronological order. The mean score of the two observers was taken as the Larsen score. If radiographs were missing for a patient, only scores of one time point were used for calculating median scores for the whole group at that time and these scores were not used for calculating progression of radiological damage.

Secondary outcome variables were the disease activity measures of the World Health Organisation/International League of Associations for Rheumatology (WHO/ILAR) core set. ${ }^{38}$ The measures were assessed at four week intervals and included a swollen joint count (66 joints), a tender joint count (68 joints), pain ( $10 \mathrm{~cm}$ visual analogue scale (VAS) with worst imaginable pain and no pain at all as extremes), fatigue $(10 \mathrm{~cm}$ VAS with extreme fatigue and no fatigue as extremes), patient's and assessor's global assessment of disease activity (five point Lickert scale ranging from no disease activity to severe disease activity), duration of early morning stiffness (in minutes), ESR (Westergren's method), and CRP. At 0, 24, and 48 weeks functional ability was measured (the validated Dutch version of the Health Assessment Questionnaire; scores from 0 (best) to 3 (worst)). Secondary end point variables were used to calculate the number of patients meeting the American College of Rheumatology (ACR) criteria for clinical improvement (ACR20, ACR50, and ACR70) ${ }^{39}$ at weeks 24 and 48.

\section{Premature discontinuation}

The study protocol required patients to stop taking the study drug for the following reasons: if two consecutive dose reductions of CsA or MTX, or both, were necessary; if the patient did

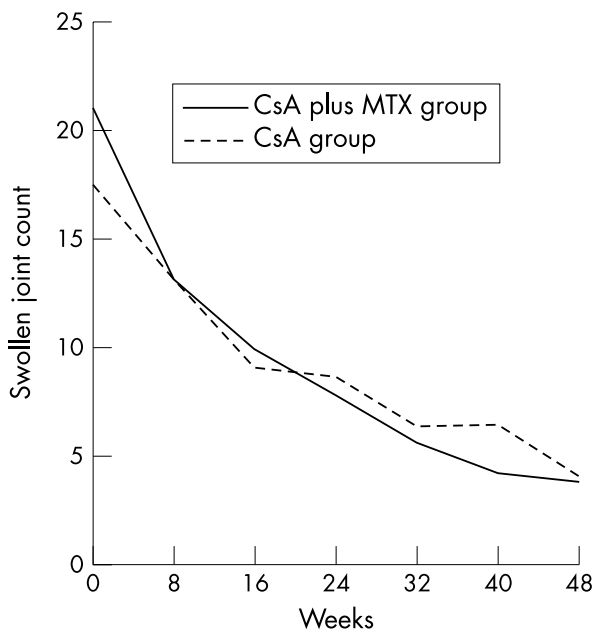

Figure 2 Swollen joint count. Course of swollen joint count over time. Mean numbers of swollen joints in each group at different times are shown.

not meet the ACR20 criteria for clinical improvement ${ }^{39} 40$ at week 24; if the study drug was discontinued for more than two weeks; if an adverse event occurred that in the opinion of the treating rheumatologist required discontinuation of CsA or MTX; and/or if consent was withdrawn by the patient. After 48 weeks of treatment with the study drug, patients could choose to continue their drug in an open fashion. If the study drug was discontinued before week 48, the treating rheumatologists were free to make their choice of further treatment.

\section{Sample size}

The expected rise in erosion score was 5 (SD 6) during 48 weeks. The required sample size to detect a difference of 3 (6) in erosion score between the monotherapy and the combination therapy group $(\alpha=0.05$, power $=0.80)$ is 60 patients in each study arm.

In advance a clinical remission rate of approximately $10 \%$ in the monotherapy group and $30 \%$ in the combination therapy group (a difference of $20 \%$ ) was assumed as clinically relevant. To detect such a difference with a power of 0.90 (two sided $\alpha=0.05$ ), a sample size of 60 patients in each arm was necessary.

\section{Analysis}

An intention to treat analysis was performed as the primary mode of analysis. If patients had stopped treatment prematurely, the last value obtained was carried forward and used in the analysis. An analysis of those completing the study was performed as a secondary analysis. Differences in efficacy measures were analysed by comparing changes from baseline. Within-group differences were tested using $t$ test statistics for paired observations; differences between treatment groups were statistically tested using $t$ test statistics for unpaired observations. Parametric and non-parametric tests were used depending on distribution of data. Dichotomous outcomes (frequencies of adverse events, premature discontinuations, ACR responses) were compared using Fisher's exact test or $\chi^{2}$ test, if appropriate. All calculations were done using SPSS software.

\section{RESULTS}

\section{Patients' characteristics}

A total of 120 patients were included in the study. Almost all patients were rheumatoid factor positive, and a considerable number already had erosions at the start of the study (table 1). The two groups were fairly well balanced, but the combination therapy group had a higher swollen joint count and a higher ESR at baseline. 
Table 3 Disease activity measures. Changes from baseline after 24 weeks' treatment. Results are shown as mean (SD)

\begin{tabular}{|c|c|c|c|c|c|}
\hline & \multicolumn{2}{|c|}{ CsA plus MTX group $(n=60)$} & \multicolumn{2}{|c|}{ CsA group $(n=60)$} & \multirow[b]{2}{*}{ p Value* } \\
\hline & Baseline & $\begin{array}{l}\text { Change at } 24 \\
\text { weeks }\end{array}$ & Baseline & $\begin{array}{l}\text { Change at } 24 \\
\text { weeks }\end{array}$ & \\
\hline Swollen joint count & 21 (10) & $-12(10)$ & $17(7)$ & $-8(9)$ & 0.05 \\
\hline Tender joint count & $26(13)$ & $-13(12)$ & 24 (12) & $-13(9)$ & 0.59 \\
\hline ESR $(\mathrm{mm} / 1 \mathrm{st} h)$ & 53 (33) & $-15(32)$ & 46 (27) & $-5(27)$ & 0.09 \\
\hline $\mathrm{C}$ reactive protein $(\mathrm{mg} / \mathrm{l})$ & $51(45)$ & -15 (19) & $49(44)$ & $-19(26)$ & 0.45 \\
\hline $\mathrm{HAQ}$ score & $1.43(0.69)$ & $-0.90(0.67)$ & $1.36(0.63)$ & $-0.87(0.65)$ & 0.80 \\
\hline VAS for pain $(\mathrm{cm})$ & $5.0(2.1)$ & $-2.0(2.5)$ & $4.8(2.4)$ & $-2.3(2.7)$ & 0.75 \\
\hline
\end{tabular}

*For the difference in change from baseline between both groups.

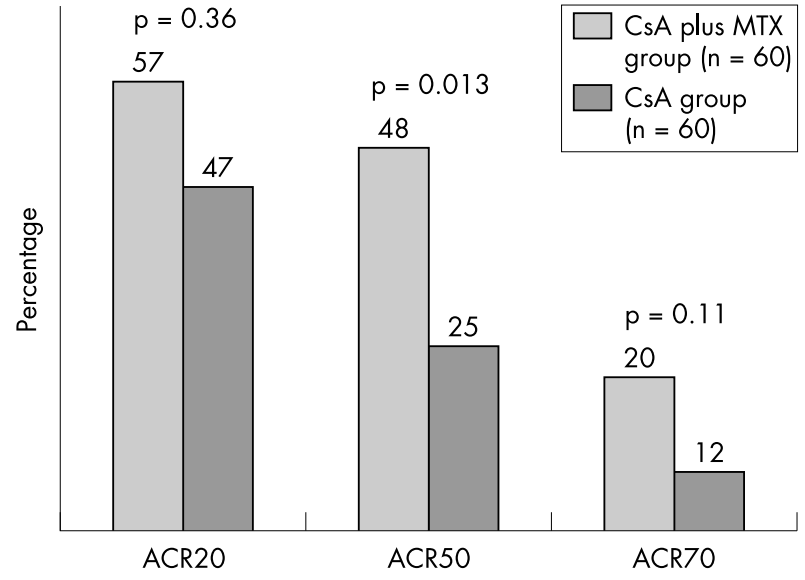

Figure 3 Improvement according to ACR criteria. Percentages of patients fulfilling ACR criteria for 20\%,50\% and $70 \%$ improvement at week 48. $p$ Values refer to between-group differences.

\section{Course of the study}

The CsA dose at 24 weeks was 3.5 (1.1) (mean (SD)) $\mathrm{mg} / \mathrm{kg} /$ day in the monotherapy group and 3.1 (1.2) $\mathrm{mg} / \mathrm{kg} / \mathrm{day}$ in the combination therapy group $(\mathrm{p}=0.107$ for the betweengroup difference). The MTX dose at week 24 was 13.7 (3.0) (mean (SD)) $\mathrm{mg} /$ week in the combination therapy group and the placebo dose $13.9(2.6)$ in the monotherapy group $(\mathrm{p}=0.73$ for the between-group difference) At week 24, 38 patients $(63 \%)$ in the combination therapy group and $40(67 \%)$ patients in the monotherapy group had achieved an ACR20 response and thus continued the study drug according to the protocol.

The mean CsA dosage at 48 weeks was 2.8 (1.0) mg/kg/day in the monotherapy group and 2.7 (1.3) $\mathrm{mg} / \mathrm{kg} / \mathrm{day}$ in the combination therapy group $(\mathrm{p}=0.89)$. The dose of MTX was $13.0(3.5) \mathrm{mg} /$ week in the combination therapy group and of placebo $14.3(2.2)$ in the monotherapy group $(\mathrm{p}=0.07)$.

\section{Adverse events}

A total number of 197 adverse events in the combination therapy group and 192 adverse events in the monotherapy group were considered related to the study drug (table 2). None of the adverse events had occurred significantly more frequently in one of the groups. After 48 weeks of treatment mean serum creatinine had increased from 74 (12) $\mu \mathrm{mol} / \mathrm{l}$ (mean (SD)) to 89 (17) $\mu \mathrm{mol} / \mathrm{l}$ in the monotherapy group $(\mathrm{p}<0.001)$, and from 72 (11) $\mu \mathrm{mol} / \mathrm{l}$ to 90 (19) $\mu \mathrm{mol} / \mathrm{l}$ in the combination therapy group $(p<0.0001) \quad(p=0.28$ for the difference between the groups). Systolic blood pressure increased from a mean of $131 \mathrm{~mm} \mathrm{Hg}$ to $139 \mathrm{~mm} \mathrm{Hg}$ in the monotherapy group and from $134 \mathrm{~mm} \mathrm{Hg}$ to $143 \mathrm{~mm} \mathrm{Hg}$ in the combination therapy group. Diastolic blood pressure increased from a mean of $80 \mathrm{~mm} \mathrm{Hg}$ to $84 \mathrm{~mm} \mathrm{Hg}$ in the monotherapy group and from 79 to $84 \mathrm{~mm} \mathrm{Hg}$ in the combination therapy group. Fifteen patients in the monotherapy group and six patients in the combination therapy group received an antihypertensive drug. Sixteen serious adverse events (six in the monotherapy group and 10 in the combination therapy group) had occurred during the study period: five acute cardiovascular events, three exacerbations of the RA needing admission to hospital, two cases of malignancy, and one case each of urosepsis, Alzheimer's disease, anaemia, sigmoid perforation, postmenopausal vaginal bleeding, and exacerbation of chronic bronchitis. None of these adverse events were thought to be related to the study drug by the judging physician.

\section{Premature discontinuations}

Twenty seven patients in the monotherapy group ( 21 because of lack of efficacy and six because of toxicity) and 26 patients in the combination therapy group ( 14 because of lack of efficacy and 12 because of toxicity) had stopped treatment during the study. In the monotherapy group, treatment was discontinued prematurely by 11 patients before week 24,10 at week 24 because of the protocol, and six after week 24 . In the combination therapy group the numbers of patients discontinuing were 15, 10, and 1, respectively. Between-group differences for the numbers discontinuing the study were not statistically significant. Hypertension or an increase in serum creatinine, or both, were more often a reason for discontinuation in the combination therapy group (nine patients $v$ two patients; $\mathrm{p}=0.05$ ).

\section{Efficacy end points}

At 48 weeks, six patients (10\%) in the combination therapy group and four patients $(7 \%)$ in the monotherapy group ( $p=0.5$ for the between-group difference) fulfilled the Pinals criteria for clinical remission

Radiological damage showed significantly more progression in the monotherapy than in the combination therapy group (fig 1). Radiographs at 48 weeks were missing in three patients in the monotherapy and two patients in the combination therapy group. At the start, the median Larsen score was 2.5 ( 25 th, 75 th centile: $0.5 ; 5.5)$ points in the monotherapy group and $2.0(0 ; 5.5)$ points in the combination therapy group. After 48 weeks, the Larsen score had increased to $10(3.5 ; 13.3)$ points in the monotherapy group and to 4 $(1.0 ; 10.5)$ points in the combination therapy group. This between-group difference was significant $(\mathrm{p}=0.004)$.

At baseline the total number of erosive joints was $0(0 ; 1)$ in both groups. At week 48 the total number of erosive joints had increased to $2.5(1 ; 5)$ in the monotherapy group and to $1.0(0$; 3 ) in the combination therapy group $(p=0.01$ for the between group difference). At baseline the total number of erosions was $0(0 ; 1)$ in both groups. At week 48 the total number of erosions had increased with $3.5(1 ; 7.5)$ in the monotherapy group and $1.5(0 ; 4)$ in the combination therapy group $(\mathrm{p}=0.02$ for the between-group difference). 
All separate parameters of disease activity had improved significantly in both groups during the study, except the ESR in the monotherapy group. Figure 2 shows an example. Apart from the decrease in ESR, the between-group differences for improvement in disease activity measures were not statistically significant, but there was always a trend towards more improvement in the combination therapy group (table 3, intention to treat analysis). Intra-articular injections were given to 11 patients (21 injections) in the monotherapy group and 18 patients ( 28 injections) in the combination therapy group respectively. Figure 3 shows the numbers of patients with different levels of ACR responses. In five of the 120 patients it was not possible to calculate clinical responses because of missing values. These patients were considered non-responders. Thirty four of the 60 patients in the combination group (57\%) and $28 / 60(47 \%)$ patients in the monotherapy group had achieved an ACR20 response at week $48(\mathrm{p}=0.36$ for the between-group difference). Twenty nine patients $(48 \%) v 15$ patients $(25 \%)$ had achieved an ACR50 response $(\mathrm{p}=0.013)$, and 12 patients $(20 \%) \vee 7$ patients $(12 \%)$ had achieved an ACR70 response $(\mathrm{p}=0.32)$.

\section{DISCUSSION}

It can be concluded from this study that a DMARD combination of CsA and MTX is better than CsA monotherapy in slowing down radiological progression. Whether the combination is more effective than CsA monotherapy in improving disease activity can be disputed. Clearly, trends in all clinical measurements support the superiority of combination therapy, but proportions of ACR20 responses are not significantly different between combination and monotherapy.

The primary end point of this study was clinical remission at 48 weeks of treatment, and it is obvious that both monotherapy and combination therapy failed to induce clinical remission in a substantial proportion of patients. However, the Pinals criteria are difficult to meet, and other studies with conventional DMARD combinations have also reported low numbers of clinical remissions. ${ }^{17}$

Despite the absence of contrast in proportions of patients with clinical remission, we found a highly significant difference in radiological progression in favour of the combination therapy group. An early deceleration of radiological progression is relevant for long term outcome. Radiological progression has been shown to be related to long term functional outcome. ${ }^{1}$

Radiological progression is considered to be a consequence of inflammatory processes, and the between-group difference in radiological progression in the absence of statistically significant differences in clinical disease activity was somewhat unexpected. A possible explanation may be that a type II error is operative. There are strong indications that patients in the combination therapy group had better clinical improvement than patients in the monotherapy group, but that the study was insufficiently powered to detect small differences. The inability to detect small differences is not a shortcoming of the study. Our randomised controlled trial (RCT) was powered to detect relevant differences in the proportion of patients with clinical remission, not in the proportion of patients with an ACR20 response. Higher response rates in the control group (CsA monotherapy in our study) deflate the power of an RCT to detect treatment effects in dichotomous outcomes, as demonstrated here. Our study can therefore neither prove nor exclude differences in clinical efficacy between the groups. As a consequence, significant deceleration of radiological progression may very well be due to non-significant but clinically relevant differences in disease activity between both groups. The results suggest that the quality rather than the quantity of clinical responses differs between the groups.

An obstacle in positioning the efficacy of the combination of CsA and MTX is the absence of a control arm with MTX monotherapy. We tried to find additional reported evidence for the effects of MTX alone in patients with RA. Despite the fact that a number of RCTs have included an MTX monotherapy arm, differences in patient population, MTX dose, and dose strategy, study duration, and type of assessments made it impossible to compare the results appropriately. Therefore we cannot conclude that the combination of MTX and CsA is better than MTX monotherapy. Limited evidence that CsA plus MTX combination therapy adds to the effect provided by MTX alone is found in a study by Marchesoni et al. ${ }^{31}$ In that randomised trial in early RA, CsA/MTX combination therapy was compared with MTX monotherapy. The data in that study showed a higher ACR20 response and significantly lower radiological progression in the combination therapy group than in the group receiving MTX alone. ${ }^{31}$ The combination MTX/CsA should also be compared with other combination therapies in early RA. The COBRA trial $(1993-97)^{17}$ focused on patients with RA with similar disease duration, similar prognostic factors, and similar disease activity. In the COBRA study patients were treated either with sulfasalazine monotherapy or with a step down combination regimen with temporary high dose prednisolone, low dose MTX, and maintenance sulfasalazine. The ACR20 criteria were met by $72 \%$ of the patients in the COBRA combination therapy group and the ACR50 improvement criteria were met by $49 \%$ of the patients at week 28. In our study ACR20 improvement criteria were met by $63 \%$ of the patients in the combination therapy group and $40 \%$ had met the ACR50 criteria at week 24 . These results suggest that the clinical effectiveness of the MTX/CsA combination may be compared with the COBRA combination therapy in patients with early RA.

A second obstacle in positioning the combination of MTX and CsA in clinical practice may be increased toxicity. All adverse events, either serious or not, were similarly divided among both groups, but there was an obvious trend towards more premature discontinuations for toxicity in the combination therapy group. It is relevant to mention the significantly higher proportion of patients withdrawing because of renal function loss and hypertension in the combination therapy group, emphasising that some increased toxicity cannot entirely be excluded.

A glance at table 2 shows that more than $50 \%$ of all reported adverse events are CsA related (creatinine rise, hypertension, hypertrichosis, gingivitis), whereas only a minority are MTX related (liver enzyme disturbances) and one might expect a more advantageous toxicity spectrum in patients treated with MTX alone. Various studies have looked at the relevance of CsA related renal function disturbances, hypertension, and so called CsA nephropathy. The common conclusions, which have led to recommendations, are that clinically relevant CsA nephropathy can be prevented by avoiding higher doses of $\mathrm{CsA},{ }^{27}$ and by not only monitoring serum creatinine but also by taking proper action when there is renal function loss. The effects of adding MTX to CsA on the renal function and blood pressure, however, have never been thoroughly investigated beyond the RCT. Any additional type of CsA related toxicity which may be due to the addition of MTX should be weighed against the benefits of this DMARD combination in efficacy.

In summary, this study of the efficacy of CsA plus MTX combination therapy in comparison with CsA monotherapy suggests they are equivalent in their induction of clinical remission. Post hoc analyses indicate that the study was probably underpowered to determine differences in induction of clinical remission. The results showed slight superiority of the drug combination in improving clinical disease activity, and definite superiority of the combination in retarding radiological progression.

\section{ACKNOWLEDGEMENT}

This study was supported by a grant from Novartis Pharma, The Netherlands. 


\section{Authors' affiliations}

A H Gerards, A P A Prins, B A C Dijkmans, VU Medical Centre and Jan van Breemen Instituut, Amsterdam, The Netherlands

R B M Landewé, H S Goei Thè, University Hospital Maastricht, The Netherlands

G A W Bruijn, Medisch Centrum Leeuwarden, The Netherlands R F J M Laan, University Medical Centre St Radboud, Nijmegen, The Netherlands

\section{REFERENCES}

1 Drossaers-Bakker KW, Kroon HM, Zwinderman AH, Breedveld FC,

Hazes JM. Radiographic damage of large joints in long-term rheumatoid arthritis and its relation to function. Rheumatology (Oxford) 2000;39:998-1003

2 Fries JF. Reevaluating the therapeutic approach to rheumatoid arthritis: the "sawtooth" strategy. J Rheumatol Suppl 1990;22:12-15.

3 Hulsmans HM, Jacobs JW, van der Heijde DM, Albada-Kuipers GA, Schenk Y, Biilsma JW. The course of radiologic damage during the first six years of rheumatoid arthritis. Arthritis Rheum 2000;43:1927-40.

4 McCarty DJ. Suppress rheumatoid inflammation early and leave the pyramid to the Egyptians [editorial]. J Rheumatol 1990;17:1115-18.

5 Pincus T, Callahan LF. Reassessment of twelve traditional paradigms concerning the diagnosis, prevalence, morbidity and mortality of rheumatoid arthritis. Scand J Rheumatol Suppl 1989;79:67-96.

6 Pincus T, Breedveld FC, Emery P. Does partial control of inflammation prevent long-term joint damage? Clinical rationale for combination therapy with multiple disease-modifying antirheumatic drugs. Clin Exp Rheumatol 1999:17:S2-7.

7 van der Heijde HA, Jacobs JW, Bijlsma JW, Heurkens AH, Booma-Frankfort $C$, van der Veen $M$, et al. The effectiveness of early treatment with "second-line" antirheumatic drugs. A randomized, controlled trial. Ann Intern Med 1996; 124:699-707.

8 van Zeben D, Hazes JM, Zwinderman AH, Vandenbroucke JP, Breedveld FC. Factors predicting outcome of rheumatoid arthritis: results of a followup study. J Rheumatol 1993;20:1288-96

9 Wilske KR, Healey LA. Remodeling the pyramid-a concept whose time has come. J Rheumatol 1989;16:565-67.

10 Alarcon GS, Lopez-Mendez A, Walter J, Boerbooms AM, Russell AS, Furst $D E$, et al. Radiographic evidence of disease progression in methotrexate treated and nonmethotrexate disease modifying antirheumatic drug treated rheumatoid arthritis patients: a meta-analysis. J Rheumatol 1992;19:1868-73.

11 Rau R, Herborn G, Karger T, Werdier D. Retardation of radiologic progression in rheumatoid arthritis with methotrexate therapy. A controlled study. Arthritis Rheum 1991;34:1236-44

12 van der Heijde DM, van Leeuwen MA, van Riel PL, Koster AM, ' $t$ Hof $M A$, van Rijswijk $M H$, et al. Biannual radiographic assessments of hands and feet in a three-year prospective followup of patients with early rheumatoid arthritis. Arthritis Rheum 1992;35:26-34.

13 van Riel PL, van der Heijde DM, Nuver-Zwart IH, van de Putte LB. Radiographic progression in rheumatoid arthritis: results of 3 comparative trials. J Rheumatol 1995;22:1797-9.

14 Weinblatt ME. Efficacy of methotrexate in rheumatoid arthritis. $\mathrm{Br} \mathrm{J}$ Rheumatol 1995;34(suppl 2):43-8

15 Haagsma CJ, van Riel PL, de Jong AJ, van de Putte LB. Combination of sulphasalazine and methotrexate versus the single components in early rheumatoid arthritis: a randomized, controlled, double-blind, 52 week clinical trial. Br J Rheumatol 1997;36:1082-8.

16 O'Dell JR, Haire CE, Erikson N, Drymalski W, Palmer W, Eckhoff PJ, et al. Treatment of rheumatoid arthritis with methotrexate alone, sulfasalazine and hydroxychloroquine, or a combination of all three medications. N Engl J Med 1996;334:1287-91.

17 Boers M, Verhoeven AC, Markusse HM, van de Laar MA, Westhovens $R$, van Denderen JC, et al. Randomised comparison of combined step-down prednisolone, methotrexate and sulphasalazine with sulphasalazine alone in early rheumatoid arthritis. Lance 1997:350:309-18

18 Tugwell P, Pincus T, Yocum D, Stein M, Gluck O, Kraag G, et al. Combination therapy with cyclosporine and methotrexate in severe rheumatoid arthritis. The Methotrexate-Cyclosporine Combination Study Group. N Engl J Med 1995;333:137-41.
19 Landewe RB, Goei The HS, van Rijthoven AW, Breedveld FC, Dijkmans BA. A randomized, double-blind, 24-week controlled study of low-dose cyclosporine versus chloroquine for early rheumatoid arthritis. Arthritis Rheum 1994;37:637-43.

20 van den Borne BE, Landewe RB, Goei The HS, Breedveld FC, Dijkmans BA. Cyclosporin A therapy in rheumatoid arthritis: only strict application of the guidelines for safe use can prevent irreversible renal function loss. Rheumatology (Oxford) 1999;38:254-9.

21 van Rijthoven AW, Dijkmans BA, Goei The HS, Hermans Montnor-Beckers ZL, et al. Cyclosporin treatment for rheumatoid arthritis: a placebo controlled, double blind, multicentre study. Ann Rheum Dis 1986;45:726-31.

22 van Rijthoven AW, Dijkmans BA, The HS, Meijers KA, Montnor-Beckers ZL, Moolenburgh JD, et al. Comparison of cyclosporine and D-penicillamine for rheumatoid arthritis: a randomized, double blind multicenter study. J Rheumatol 1991;18:815-20.

23 Verhoeven AC, Boers $M$, Tugwell P. Combination therapy in rheumatoid arthritis: updated systematic review. Br J Rheumatol 1998;37:612-19.

24 Tugwell P, Bombardier C, Gent M, Bennett KJ, Bensen WG, Carette S, et al. Low-dose cyclosporin versus placebo in patients with rheumatoid arthritis. Lancet 1990;335:1051-5.

25 Kruger K, Schattenkirchner M. Comparison of cyclosporin A and azathioprine in the treatment of rheumatoid arthritis - results of a double-blind multicentre study. Clin Rheumatol 1994;13:248-55.

26 Landewe RB, Goei The HS, van Rijthoven AW, Rietveld JR, Breedveld $\mathrm{FC}$, et al. Cyclosporine in common clinical practice: an estimation of the benefit/risk ratio in patients with rheumatoid arthritis. J Rheumatol 1994;21:1631-6.

27 Rodriguez F, Krayenbuhl JC, Harrison WB, Forre O, Dijkmans BA, Tugwell $P$, et al. Renal biopsy findings and followup of renal function in rheumatoid arthritis patients treated with cyclosporin A. An update from the International Kidney Biopsy Registry. Arthritis Rheum 1996;39:1491-8.

28 Tugwell P, Baker P. Guidelines for the use of cyclosporine in rheumatoid arthritis. Clin Rheumatol 1995; 14(suppl 2):37-41.

29 Ferraccioli GF, Della Casa-Alberighi O, Marubini E, Priolo F, Mathieu A, Fantini $F$, et al. Is the control of disease progression within our grasp? Review of the GRISAR study. (Gruppo Reumatologi Italiani Studio Artrite Reumatoide). Br J Rheumatol 1996;35(suppl 2):8-13.

30 Forre $\mathbf{O}$. Radiologic evidence of disease modification in rheumatoid arthritis patients treated with cyclosporine. Results of a 48-week multicenter study comparing low-dose cyclosporine with placebo. Norwegian Arthritis Study Group. Arthritis Rheum 1994;37:1506-12.

31 Marchesoni A, Battafarano N, Arreghini M, Benedetta P, Cagnoli M, Tosi S. Slower radiographic progression in patients with early rheumatoid arthritis treated with cyclosporine and methotrexate combination therapy [abstract]. Arthritis Rheum 2001;44(suppl):S371.

32 Furst DE. Clinical pharmacology of combination DMARD therapy in rheumatoid arthritis. J Rheumatol Suppl 1996;44:86-90.

33 Arnett FC, Edworthy SM, Bloch DA, McShane DJ, Fries JF, Cooper NS et al. The American Rheumatism Association 1987 revised criteria for the classification of rheumatoid arthritis. Arthritis Rheum 1988;31:315-24.

34 Cockcroft DW, Gault MH. Prediction of creatinine clearance from serum creatinine. Nephron 1976;16:31-41.

35 Pinals RS, Masi AT, Larsen RA. Preliminary criteria for clinical remission in rheumatoid arthritis. Arthritis Rheum 1981:24:1308-15.

36 Larsen A. How to apply Larsen score in evaluating radiographs of rheumatoid arthritis in long-term studies. J Rheumatol 1995;22:1974-5.

37 Paimela L, Laasonen L, Helve T, Leirisalo-Repo M. Comparison of the original and the modified Larsen methods and the Sharp method in scoring radiographic progression in early rheumatoid arthritis. J Rheumatol 1998;25:1063-6.

38 Boers M, Tugwell P, Felson DT, van Riel PL, Kirwan JR, Edmonds JP, et al World Health Organization and International League of Associations for Rheumatology core endpoints for symptom modifying antirheumatic drugs in rheumatoid arthritis clinical trials. J Rheumatol Suppl 1994;41:86-9.

39 Felson DT, Anderson JJ, Meenan RF. The efficacy and toxicity of combination therapy in rheumatoid arthritis. A meta-analysis. Arthritis Rheum 1994:37:1487-91.

40 Felson DT, Anderson JJ, Boers M, Bombardier C, Furst D, Goldsmith C, et al. American College of Rheumatology. Preliminary definition of improvement in rheumatoid arthritis. Arthritis Rheum 1995;38:727-35. 


\section{MATTERS ARISING}

If you have a burning desire to respond to a paper published in the Annals of the Rheumatic Diseases, why not make use of our "rapid response" option?

Log on to our website (www. annrheumdis. com), find the paper that interests you, and send your response via email by clicking on "eletters" option in the box at the top right hand corner.

Providing it isn't libellous or obscene, it will be posted within seven days. You can retrieve it by clicking on "read eletters" on our homepage.

The editor will decide as before whether also to publish it in a future paper issue.

\section{Cyclosporin and methotrexate therapy}

We read with interest the report by Gerard et al on the efficacy of cyclosporin monotherapy compared with methotrexate and cyclosporin combination therapy in patients with early rheumatoid arthritis. ${ }^{1}$ It is pleasing to see the increasing trend of publications looking at appropriate management strategies in early disease. We have previously reported a study comparing combination methotrexate, cyclosporin A, and intraarticular corticosteroids with sulfasalazine in a similar patient group. ${ }^{2}$

In our 48 week study there was no difference in American College of Rheumatology response, remission rates, or radiographic progression between the two groups at 48 weeks. The current cohort is similar in age though with shorter disease duration and a higher proportion of rheumatoid factor positive patients. Our study did show significantly fewer withdrawals due to lack of efficacy in the combination group than in the sulfasalazine monotherapy group (1/ $40 v 10 / 42$ ), adding weight to the suggestion of the current study which demonstrated more effective retardation of radiographic progression in the combination treated group. These data suggest that the combination may be more effective in a larger study group.

However, combinations involving cyclosporin must be considered in the light of its significant toxicity. Both the current study and our own had significant periods of modestly raised serum creatinine and episodes of hypertension.

The difference in radiographic progression in the Gerards' study compared with our own is interesting. The mean doses of cyclosporin and methotrexate in the combination therapy group at 48 weeks were similar in both studies, and it tempting to speculate that the difference in outcomes between the two studies reflects the difference in the comparator treatment-namely, sulfasalazine versus cyclosporin monotherapy. It appears that monotherapy with sulfasalazine is more effective than cyclosporin at retarding disease progression measured by radiographic erosion progression rate. We note that the corticosteroid dose in the Gerards' trial is not reported, although it was presumably low judged by the number of injections given. Thus it would appear reasonable to conclude that although cyclosporin (as suggested by its mode of action) is effective in early disease, the benefits are insufficient compared with its toxicity to warrant routine use as first line treatment, either as monotherapy or in combination.

P G Conaghan, P Emery Academic Unit of Musculoskeletal Disease, University of Leeds, UK

Correspondence to: Professor Paul Emery, Department of Rheumatology Old Nurses Home, Great George Street, Leeds LS1 3EX, UK; p.emery@leeds.ac.uk

\section{References}

1 Gerards AH, Landewé RB, Prins APA, Bruyn GAW, Goei Thè HS, Laan RFJM, et al. Cyclosporin A monotherapy versus cyclosporin A and methotrexate combination therapy in patients with early rheumatoid arthritis: a double blind randomised placebo controlled trial. Ann Rheum Dis 2003:62:291-6.

2 Proudman SM, Conaghan PG, Richardson C, Griffiths B, Green MJ, McGonagle D, et al. Treatment of poor-prognosis early rheumatoid arthritis: a randomized study of treatment with methotrexate cyclosporin $A$, and intraarticular corticosteroids compared with sulfasalazine alone. Arthritis Rheum 2000;43:1809-19.

\section{Authors' reply}

With interest we read the remarks of Conaghan and Emery concerning the differences between our report and the study of Proudman et al. ${ }^{1}$

The Proudman study compared the combination of methotrexate, cyclosporin, and intra-articular injections with sulfasalazine monotherapy in rheumatoid arthritis (RA). Like in our study, Proudman et al noticed fewer withdrawals due to inefficacy in the combination therapy group, which underlines the importance of testing combination therapy in early disease.

Although tempting, it is difficult to compare outcome measures in Proudman's study and our study because of the differences in the study group and the lack of randomisation. We think that erosion scores in the two studies should not be compared when the interobserver differences are not known. We do not know if sulfasalazine or cyclosporin is better at retarding radiological progression, on the basis of the information from these two studies.

Conaghan and Emery conclude that cyclosporin cannot be used as a first line treatment in early RA, either as monotherapy or in combination therapy. We do not share that view. Cyclosporin toxicity was well controlled in a earlier study in early RA. ${ }^{2}$ The issue of nephrotoxicity with any treatment including cyclosporin is not resolved, although the guidelines state that toxicity is acceptable when dosage rules are closely guarded..$^{3-6} \mathrm{We}$ did not advocate the combination of methotrexate and cyclosporin as first line treatment in early RA because the data on efficacy were not sufficient. On the other hand, there is no evidence that the combination cannot be used because of toxicity.

A H Gerards, B A C Dijkmans

VU Medical Centre and Jan van Breemen Instituut, Amsterdam, The Netherlands

R B M Landewé

University Hospital Maastricht, The Netherlands

Correspondence to: $\operatorname{Dr} \mathrm{A} H$ Gerards, Department of Rheumatology, Vlietland Ziekenhuis, 3116 BA Schiedam, The Netherlands; agerards@ssvz.nl

\section{References}

1 Proudman SM, Conaghan PG, Richardson C, Griffiths B, Green MJ, McGonagle D, et al. Treatment of poor-prognosis early rheumatoid arthritis. A randomized study of treatment with methotrexate, cyclosporin $A$, and intraarticular corticosteroids compared with sulfasalazine alone. Arthritis Rheum 2000;43:1809-19.

2 Landewe RB, Goei The HS, van Rijthoven AW Breedveld FC, Dijkmans BA. A randomized, double-blind, 24-week controlled study of lowdose cyclosporine versus chloroquine for early rheumatoid arthritis. Arthritis Rheum 1994:37:637-43.

3 van den Borne BE, Landewe RB, Goei The HS, Breedveld FC, Dijkmans BA. CyclosporinA therapy in rheumatoid arthritis: only strict application of the guidelines for safe use can prevent irreversible renal function loss. Rheumatology (Oxford) 1999;38:254-9.

4 Landewe RB, Goei The HS, van Rijthoven AW, Rietveld JR, Breedveld FC, Dijkmans BA. Cyclosporine in common clinical practice: an estimation of the benefit/risk ratio in patients with rheumatoid arthritis. J Rheumatol 1994:21:1631-6.

5 Rodriguez F, Krayenbuhl JC, Harrison WB Forre O, Dijkmans BA, Tugwell P, et al. Renal biopsy findings and followup of renal function in rheumatoid arthritis patients treated with cyclosporin A. Arthritis Rheum 1996;39:1491-8.

6 Tugwell P, Baker P. Guidelines for the use of cyclosporine in rheumatoid arthritis. Clin Rheumatol 1995; 14(suppl 2):37-41

\section{Cyclosporin $A$ in rheumatoid arthritis}

We read the paper by Gerard et al with interest. ${ }^{1}$ The authors are to be commended for the modest claims they make about the results of their study. They show that a combination of methotrexate and cyclosporin better retards radiographically visible progression than cyclosporin alone after one year in patients with early rheumatoid arthritis (RA). It raises the question whether cyclosporin A still has a place in the early treatment of this disease. One shortcoming of this study as stated in the paper is the lack of a methotrexate only arm. Furthermore, the study did not use optimal doses of methotrexate in the combined arm. Therefore, the possibility that the additional beneficial effects achieved in the combined arm at least in part might have been seen with methotrexate given in monotherapy cannot be excluded. The authors cite a number of studies supporting a retarding effect of cyclosporin, but fail to cite evidence that cyclosporin is not better 
than sodium aurothiomalate (Myocrisin) in this respect. ${ }^{2}$ This study stratified for the use of corticosteroids, in contrast with another often cited paper which claims that cyclosporin is better than a number of comparative disease modifying antirheumatic drugs, including chloroquine. ${ }^{3}$ The three year follow up of the stratified study still showed no difference in radiographic progression between the arms. Despite strict adherence to safety rules about dosing of cyclosporin, adverse renal effects were seen, which were not completely reversible. ${ }^{4}$

The safety issue is, however, unsettled, and the main purpose of our comment. Cyclosporin is an indispensable drug in transplantation medicine and of unquestionable value in the treatment of unresponsive patients with conditions such as vasculitis and uveitis. A prospective biopsy study in patients with psoriasis and psoriatic arthritis showed that all of around 30 patients developed interstitial fibrosis and arteriolar wall thickening characteristic of cyclosporin damage. ${ }^{5}$ A similar study in patients with RA has not been published. A study published in 1996 stated: "Long term continuous treatment of RA with low dose cyclosporin does not result in more structural nephropathy than the disease process itself, in spite of substantial and persistent deterioration of the renal function". ${ }^{6}$ This study compared renal biopsy results from 11 patients with RA treated for 24 months with 22 necropsy specimens. Although no morphological differences were apparent, creatinine clearance had diminished by $26 \%$ in the patients. The accompanying editorial pointed out the weaknesses of the study, based on small size, lack of pretreatment biopsies, and uncertainty about the control group.

A registry based study was published in 1996, ${ }^{8}$ consisting of 60 patients in all. It was not stated how the patients were selected for biopsy. The authors concluded that the low doses that had been given to 22 of the patients had not caused any renal damage. A more recent analysis performed in 1998 of cyclosporin induced nephrotoxicity in autoimmune diseases concluded, however, that the treatment even with doses of $5 \mathrm{mg} / \mathrm{kg} /$ day or lower was not without risks, and that renal biopsies should be seriously considered in patients who develop even slight renal function impairment. ${ }^{9}$ This view is based on the slowly progressive interstitial fibrosis and arterial wall thickening characteristic of cyclosporin toxicity. A review published in 1999 examines the subject of renal toxicity and long term treatment with cyclosporin of autoimmune disease..$^{10}$ It concludes that even strict adherence to recommended rules carries a substantial risk for irreversible changes after two years' treatment, and emphasises the need for rigorous risk-benefit analysis in each patient. In view of the lack of long term safety data based inter alia on systematic prospective biopsy results we feel that one should not use cyclosporin in patients with RA until other possible treatments have failed.

After the initial submission of this letter Fox et al published a report showing that cyclosporin A when given to patients with RA also treated with methotrexate, inhibits the oxidation of methotrexate to an inactive metabolite and thereby potentiates the effect of methotrexate. This will thus lead to a potentiation of the methotrexate effect and increased risks of adverse reactions when the drugs are combined.
T Saxne, F A Wollheim

Department of Rheumatology, Lund University Hospital, S-221 85 Lund, Sweden

Correspondence to: Professor F A Wollheim; Frank.Wollheim@reum.lu.se

\section{References}

1 Gerards AH, Landewe RB, Prins AP, Bruyn GA, Goei The HS, Laan RF, et al. Cyclosporin A monotherapy versus cyclosporin A and methotrexate combination therapy in patients with early rheumatoid arthritis: a double blind randomised placebo controlled trial. Ann Rheum Dis 2003;62:291-6.

2 Zeidler HK, Kvien TK, Hannonen P, Wollheim FA, Forre $\mathrm{O}$, Geidel $\mathrm{H}$, et al. Progression of joint damage in early active severe rheumatoid arthritis during 18 months of treatment: comparison of low-dose cyclosporin and parenteral gold. Br J Rheumatol 1998;37:874-82.

3 Pasero G, Priolo F, Marubini E, Fantini F, Ferraccioli G, Magaro $M$, et al. Slow progression of joint damage in early rheumatoid arthritis treated with cyclosporin A. Arthritis Rheum 1996;39:1006-15.

4 Kvien TK, Zeidler HK, Hannonen P, Wollheim FA, Forre O. Hafstrom I, et al. Long term efficacy and safety of cyclosporin versus parenteral gold in early rheumatoid arthritis: a three year study of radiographic progression, renal function, and arterial hypertension. Ann Rheum Dis 2002:61:51 1-16.

5 Zachariae H, Kragballe K, Hansen HE, Marcussen N, Olsen S. Renal biopsy findings in long-term cyclosporin treatment of psoriasis. Br J Dermatol 1997:136:531-5.

6 Landewe RB, Dijkmans BA, van der Woude FJ, Breedveld FC, Mihatsch MJ, Bruijn JA. Longterm low dose cyclosporine in patients with rheumatoid arthritis: renal function loss without structural nephropathy. J Rheumatol 1996;23:61-4.

7 Pei Y. Chronic cyclosporine nephrotoxicity in rheumatoid arthritis. J Rheumatol 1996;23:4-5.

8 Rodriguez F, Krayenbuhl JC, Harrison WB, Forre O, Dijkmans BA, Tugwell P, et al. Renal biopsy findings and followup of renal function in rheumatoid arthritis patients treated with cyclosporin A. An update from the International Kidney Biopsy Registry. Arthritis Rheum 1996;39:1491-8.

9 Vercauteren SB, Bosmans JL, Elseviers MM, Verpooten GA, De Broe ME. A meta-analysis and morphological review of cyclosporine-induced nephrotoxicity in auto-immune diseases. Kidney nephrotoxicity in auto-

10 Zachariae H. Renal toxicity of long-term cyclosporin. Scand J Rheumatol 1999:28:65-8.

11 Fox RI, Morgan SL, Smith HT, Robbins BA Choc MG, Baggott JE. Combined oral cyclosporin and methotrexate therapy in patients with rheumatoid arthritis elevates methotrexate levels and reduces 7 -hydroxymethotrexate levels when compared with methotrexate alone.

Rheumatology (Oxford) 2003;42:989-94.

\section{Authors' reply}

We thank Saxne and Wollheim for their kind remarks. Indeed, we were interested in whether the beneficial effects in the combination therapy group should be ascribed to the concerted action of the combining drugs rather than to the action of methotrexate alone. To test this hypothesis we selected a sample of 41 patients out of a cohort of 411 patients who all had participated in the methotrexate/folate supplementation study which was published recently. ${ }^{1}$ These 41 patients were matched for age, sex, disease duration, and clinical disease activity. All 41 patients had early rheumatoid arthritis (RA) and were treated with methotrexate as their first disease modifying antirheumatic drug (DMARD; median dose $15 \mathrm{mg} /$ week). Of these 41 patients, $19(47 \%)$ had an
American College of Rheumatology (ACR)20 response after one year of treatment, $9(22 \%)$ had an ACR50 response, and $3(8 \%)$ had an ACR70 response. The proportions of patients who had responded to methotrexate monotherapy were in the same range as the proportions of patients who had responded to cyclosporin monotherapy, and substantially lower than the proportions who responded to cyclosporin plus methotrexate combination therapy in our study.

These results give an indication that the effects seen in the combination therapy arm cannot be ascribed to methotrexate alone. Recently, Marchesoni et al published the results of a study showing that the combination of cyclosporin and methotrexate is more effective in retarding radiological progression than methotrexate alone. ${ }^{\text {la }}$

The subject of nephrotoxicity of cyclosporin remains highly controversial.

We agree with Saxne and Wollheim that structural damage to the kidney is not clearly demonstrated in patients with RA treated with cyclosporin. Reports in other autoimmune diseases cannot be extrapolated to RA but warrant a careful approach. Most reports on cyclosporin in RA state that impairment of the renal function is reversible if dosage guidelines are strictly followed..$^{2-5}$ The study of Boers et al showed that nephrotoxicity is reversible. ${ }^{6}$ The study of Kvien et $a l^{7}$ is an extension of the study of Zeidler et al. ${ }^{8}$ In the study of Zeidler dose reduction of cyclosporin was required if serum creatinine rose to $>50 \%$ above the baseline, while guidelines recommend $30 \%$. In the study of Kvien it is clear that it was mainly patients who had a rise in creatinine $>50 \%$ during cyclosporin treatment who were at risk of creatinine remaining high after discontinuation of cyclosporin. This again underlines the importance of the guidelines. We advocate the use of creatinine clearance measurement or calculation before starting cyclosporin treatment, to select patients at risk.

Data on renal function should be viewed from the point of view that renal function loss is common in patients with RA. ${ }^{9}$ It is not clear whether the patients in the study of Zeidler and Kvien who were treated on the basis of the cyclosporin guidelines (a rise in creatinine no more than $30 \%$ is acceptable) were subjected to a greater renal function loss than other patients with RA. Unfortunately, studies from Zachariae (on psoriasis and with higher cyclosporin dosages) and Vercauteren (not concerning patients with RA) do not shed light on this topic. Our conclusion is that on the basis of current knowledge on toxicity there is no reason to withhold cyclosporin from all patients with RA. However, questions about efficacy still have to be answered.

A H Gerards, B A C Dijkmans VU Medical Centre and Jan van Breemen Instituut, Amsterdam, The Netherlands

R B M Landewé

University Hospital Maastricht, The Netherlands

Correspondence to: $\operatorname{Dr}$ A H Gerards, Department of Rheumatology, Vlietland Ziekenhuis, 3116 BA Schiedam, The Netherlands; agerards@ssvz.n

\section{References}

1 van Ede $A E$, Laan RF, Rood MJ, Huizinga TW, van de Laar MA, van Denderen CJ, et al. Effect of folic or folinic acid supplementation on the toxicity and efficacy of methotrexate in rheumatoid 
arthritis: a forty-eight week, multicenter, randomized, double-blind, placebo-controlled study. Arthritis Rheum 2001;44:1515-24.

la Marchesoni A, Battafarano N, Arreghini M, Panni B, Gallazzi M, Tosi S. Radiographic progression in early rheumatoid arthritis: a 12 month randomized controlled study comparing the combination of cyclosporin and methotrexate with methotrexate alone. Rheumatology (Oxford) 2003. (Epub ahead of print.)

2 van den Borne BE, Landewe RB, Goei The HS Breedveld FC, Dijkmans BA. Cyclosporin A therapy in rheumatoid arthritis: only strict application of the guidelines for safe use can prevent irreversible renal function loss. Rheumatology (Oxford) 1999;38:254-9.

3 Landewe RB, Goei The HS, van Rijthoven AW, Rietveld JR, Breedveld FC, Dijkmans BA. Cyclosporine in common clinical practice: an estimation of the benefit/risk ratio in patients with rheumatoid arthritis. J Rheumatol 1994:21:1631-6.

4 Rodriguez F, Krayenbuhl JC, Harrison WB, Forre O, Dijkmans BA, Tugwell P, et al. Renal biopsy findings and followup of renal function in rheumatoid arthritis patients treated with cyclosporin A. An update from the International Kidney Biopsy Registry. Arthritis Rheum 1996;39:1491-8.

5 Tugwell P, Baker P. Guidelines for the use of cyclosporine in rheumatoid arthritis. Clin Rheumatol 1995; 14(suppl 2):37-41.

6 Boers M, Dijkmans BAC, van Rijthoven AWAM, Goei The HS, Cats A. Reversible nephrotoxicity of cyclosporine in rheumatoid arthritis. J Rheumatol 1990;17:38-42.

7 Kvien TK, Zeidler HK, Hannonen P, Wollheim FA, Forre $\mathrm{O}$, Hafstrom I, et al. Long term efficacy and safety of cyclosporin versus parenteral gold in early rheumatoid arthritis: a three year study of radiographic progression, renal function, and arterial hypertension. Ann Rheum Dis 2002;61:511-16.

8 Zeidler HK, Kvien TK, Hannonen P, Wollheim FA, Forre $\mathrm{O}$, Geidel $\mathrm{H}$, et al. Progression of joint damage in early active severe rheumatoid arthritis during 18 months of treatment: comparison of low-dose cyclosporin and parenteral gold. Br J Rheumatol 1998;37:874-2.

9 Boers M. Renal disorders in rheumatoid arthritis. Semin Arthritis Rheum 1990;20:57-68.

\section{Is methotrexate osteopathy a form of bone idiosyncrasy?}

I read the letter about low dose methotrexate (MTX) osteopathy with mixed feelings. On the one hand, it is not unusual for a woman to develop insufficiency bone fracture after 25 years of prednisone treatment. Longstanding inflammatory joint disease also affects bone. The patient had an active disease that is associated with osteoclast activation mediated by tumour necrosis factor-osteoprotegerin. However, the authors underestimated other possible factors which might have had an influence on bone density. Menstrual cycle status was not discussed. Results of bone density assessment were not described despite long term steroid treatment. Risk factors such as family history, smoking, diet, and physical activity were not analysed

of note, besides pelvic fracture, increased technetium-99m uptake was seen in joint areas with normal standard radiographs. This may be due to active arthritis and enthesopathy. We can draw no conclusions about the duration of the bone scan findings. Data about previous scans are absent. MTX in vitro does not affect the proliferation and further maturation of osteoblasts. ${ }^{2}$ No adverse effect of low dose MTX (<30 mg/week) on bone formation in RA has been found ${ }^{3}$ Studies have shown that low dose MTX treatment did not cause a decrease of bone density and was similar to that of the control groups. ${ }^{4-6}$ Summarising previous studies we can state that most patients have no increased risk of MTX osteopathy. Osteopathy resulting from high dose MTX treatment in children with malignancy occurs only in $9 \%$ of patients.

On the other hand, however, this young woman developed pelvic spontaneous fracture three months after the onset of MTX treatment. Severe leg pains increased by weight bearing and relieved by rest followed after four months of treatment. Such a rapid occurrence suggests hypersensitivity of the delayed type with targeting to bones. Bone targeted drug idiosyncrasy may also be considered. Very delayed drug induced hypersensitivity affecting fat tissue of the abdomen has been reported previously. ${ }^{8}$ Other tissues may also be affected. Drug sensitivity tests may be helpful.

High and low dose MTX osteopathy have similar signs and symptoms, including a triad of severe low extremity pain (distal tibia), osteoporosis, and compression bone fractures occurring spontaneously or after minimal trauma. Both may develop even over a short period of time after the onset of MTX treatment. $^{19}$ In both osteoporosis dosage groups scurvy-like lines may be seen on $x$ ray examination, which may be normal at the start. Because the multiple controls receiving the same treatment in both groups do not have signs of such severe osteoporosis, it is assumed that an as yet unknown cause may be responsible. ${ }^{10}$ We propose hypersensitivity reaction or idiosyncrasy, rapidly affecting bone tissue, may be such causes. There have been comparable reported rates of high and low dose (different by 70-100 fold) MTX

Table 1 Publications on high dose and low dose MTX osteopathy since the first report in 1970

\begin{tabular}{|c|c|}
\hline $\begin{array}{l}\text { High dose } \\
\text { Cumulative dose: } 7.5-144 \mathrm{~g} / \mathrm{m}^{2} \\
\text { Onset: } 4-11 \text { months }\end{array}$ & $\begin{array}{l}\text { Low dose } \\
\text { Cumulative dose: } 97.5 \mathrm{mg}-3.5 \mathrm{~g} / \mathrm{m}^{2} \\
\text { Onset: } 3 \text { months- } 8.5 \text { years }\end{array}$ \\
\hline $\begin{array}{l}\text { Ragab et al, } 1970 \\
\text { Newman et al, } 1973 \\
\text { O'Regan et al, } 1973 \\
\text { Koller et al, } 1976 \\
\text { Stanisavlievic et al, } 1977 \\
\text { Jaffe et al, } 1987 \\
\text { Vassilopoulou-Sellin et al, } 1992 \\
\text { Meister et al, } 1994 \\
\text { Exclund et al, } 1997\end{array}$ & $\begin{array}{l}\text { Preston SJ et al, } 1993 \\
\text { Shapira D et al, } 1995 \\
\text { Maenaut et al, } 1996 \\
\text { Zonneveld et al, } 1996 \\
\text { Bologna et al, } 1996 \\
\text { Singwe M et al, } 1998 \\
\text { Stevens et al, } 2001 \\
\text { Wijnands et al, } 2001 \\
\text { Rudler et al, } 2003\end{array}$ \\
\hline
\end{tabular}

osteopathy, independent of cumulative doses, ${ }^{7}$ pointing to the possible role of idiopathic or hypersensitivity aetiologies (table 1). Bone pain diminished within one month after stopping MTX treatment in both groups, and $x$ ray findings returned to normal 5-7 months later. ${ }^{7}$ Proposed bone hypersensitivity in MTX osteopathy may be compared with hypersensitivity lung or liver disease due to MTX treatment. These serious complications of MTX treatment may follow any cumulative dose of the drug. Recognising the phenomenon of MTX bone idiosyncrasy or hypersensitivity may prevent the unnecessary or harmful proposal that MTX treatment is a risk factor for osteoporosis and should be relatively contraindicated in patients with multiple risk factors for osteoporosis.

A P Rozin

Bat Galim, Rambam Medical Centre, PO Box 9602 Haifa, Israel

Correspondence to: Dr A P Rozin, B Shine Department of Rheumatology, Rambam Medical Centre, PO Box 9602, Haifa 31096, Israel; a rozin@rambam. health.gov.il

\section{References}

1 Rudler M, Pouchot J, Paycha F, Gentelle S, Grasland A, Vinceneux P. Low dose methotrexate osteopathy in a patient with polyarticular juvenile idiopathic arthritis. Ann Rheum Dis 2003;62:588-9.

2 Minaur NJ, Jefferiss C, Bhalla AK, Beresford JN. Methotrexate in the treatment of rheumatoid arthritis. I. In vitro effects on cells of the osteoblast lineage. Rheumatology (Oxford) 2002;41:735-40

3 Minaur NJ, Kounali D, Vedi S, Compston JE, Beresford JN, Bhalla AK. Methotrexate in the treatment of rheumatoid arthritis. II. In vivo effects on bone mineral density. Rheumatology (Oxford) 2002;41:741-9.

4 Kita K, Sierakowski S. The effect of low dose methotrexate treatment on bone mineral density in patients with rheumatoid arthritis. Pol Merkuriusz Lek 2002;12:122-5.

5 Cranney AB, McKendry RJ, Wells GA, Ooi DS, Kanigsberg ND, Kraag GR, et al. The effect of low dose methotrexate on bone density. J Rheumatol 2001;28:2395-9.

6 Mazzantini M, Di Munno O, Incerti-Vecchi L Pasero G. Vertebral bone mineral density changes in female rheumatoid arthritis patients treated with low-dose methotrexate. Clin Exp Rheumatol 2000;18:327-31.

7 Ecklund K, Laor T, Goorim AM, Connolly LP Jaramillo D. Methotrexate osteopathy in patients with osteosarcoma. Radiology 1997;202:543-7.

8 Rozin A, Bishara B, Ben-Izhak O, Fischer D, Carter A, Edoute Y. Fibrosing omental panniculitis and polyserositis associated with long-term treatment by paroxetine. IMAJ 2000;2:714-16.

9 Zonneveld IM, Bakker WK, DiJkstra PF, Bos JD, van Soesbergen RM, Dinant HJ. Methotrexate osteopathy in long-term, low-dose methotrexate treatment for psoriasis and rheumatoid arthritis. Arch Dermatol 1996;132:184-7.

10 Kooller A, Fill H, Kurz R, Riccabona G, Haas H. Osteopathy due to methotrexate. Osterr Kneipp Mag 1976;3:63-9.

\section{Low dose methotrexate osteopathy in a patient with polyarticular juvenile idiopathic arthritis}

We read with some surprise the article by Rudler and colleagues proposing a case of a 36 year old woman with methotrexate (MTX) osteopathy. ${ }^{1}$ The authors report insufficiency fractures after low dose MTX treatment for 
three months and further fractures two months later.

They suggest that MTX osteopathy may be more common than expected in patients treated with low dose methotrexate, yet all the evidence suggests the opposite. MTX is now the most commonly prescribed disease modifying antirheumatic drug for rheumatoid arthritis in America and parts of Europe. $^{23}$ We conservatively estimate that 120000 patients receive low dose MTX in the UK alone, with historically a greater proportion of patients in America receiving the drug. Yet cases of proposed MTX osteopathy with low dose treatment are vanishingly rare (six reported cases in adults). Moreover, recent data suggest that low dose MTX has no effect on bone turnover at all.

In this case only a low dose of MTX was used and is the suggested cause of the fractures. Data from paediatric cases suggest that extremely high doses of MTX $\left(20 \mathrm{~g} / \mathrm{m}^{2}\right.$, $80 \mathrm{~g} / \mathrm{m}^{2}$, and $135 \mathrm{~g} / \mathrm{m}^{2}$ ) are associated with MTX osteopathy. ${ }^{4}$ Smaller cumulative doses have been implicated in adults, but in the only other published case with short duration (nine months) the patient received almost fivefold more MTX..$^{5}$ It is surprising that the authors do not comment on the role of the high doses of prednisolone treatment (estimated cumulative dose of $92 \mathrm{~g}$ ) or the presence of inflammatory disease over 27 years, both important risk factors for insufficiency fractures.

There is a growing body of evidence to refute the fact that MTX has any clinically significant effect on bone mineral density (BMD) or a significant impact on the osteoblast lineage. Patel et al carried out a prospective study of patients with psoriasis and low dose MTX treatment, and reported no significant change in markers of bone turnover or BMD after 21 months' follow up. Minaur et al found that the proliferation and maturation of cells of the osteoblast lineage were not affected by MTX. ${ }^{6}$ In a study of 116 patients, no direct association of MTX with BMD loss or bone turnover markers was found, and in a small subset, no impact on bone formation was shown by biopsy.

There appears to be sufficient evidence to doubt the pathogenic role of MTX in this case. Further information about the treatment of the patient in the study of Rudler $e t$ al, her BMD, parathyroid hormone levels, and long term outcome are necessary. Did she receive any treatment at all after her initial fractures? In the last paragraph the authors refer to stress fractures. Are they implying that undue stress or activity contributed to the clinical picture? We believe they should be described as insufficiency fractures. The former are fractures occurring in otherwise normal bones by an abnormally applied mechanical load and the latter are due to abnormal bone.

Currently, it is thought that the possibility of a detrimental impact of MTX on the skeleton, even with concomitant corticosteroids, is low. It is important to emphasise that MTX has had a major impact in improving the health and bones (through corticosteroid sparing) of patients with inflammatory arthritis as well as other inflammatory conditions, which greatly outweighs any possible detrimental effects

M A Quinn, M J Green, A K S Gough Harrogate District Hospital, UK
Correspondence to: $\operatorname{Dr}$ A K S Gough, Harrogate District Hospital; andrew.gough@hhc-tr.northy.nhs.uk

\section{References}

1 Rudler M, Pouchot J, Paycha F, Gentelle S, Grasland A, Vinceneux P. Low dose methotrexate osteopathy in a patient with polyarticular juvenile idiopathic arthritis. Ann Rheum Dis 2003:62:588-9.

2 Mikuls TR, O'Dell J. The changing face of rheumatoid arthritis therapy: results of serial surveys. Arthritis Rheum 2000:43:464-5.

3 Klauka T, Kaarela K. Methotrexate is the leading DMARD in Finland. Ann Rheum Dis 2003:62:494

4 Meister B, Gassner I, Streif W, Dengg K, Fink FM. Methotrexate osteopathy in infants with tumors of the central nervous system. Med Pediatr Oncol 1994; 23:493-6.

5 Zonneveld IM, Bakker WK, Dijkstra PF, Bos JD, van Soesbergen RM, Dinant HJ. Methotrexate osteopathy in long-term, low-dose methotrexate treatment for psoriasis and rheumatoid arthritis. Arch Dermatol 1996;132:184-7.

6 Patel S, Patel G, Johnson D, Ogunremi L, Barron J. Effect of low dose weekly methotrexate on bone mineral density and bone turnover. Ann Rheum Dis 2003;62:186-7.

7 Minaur NJ, Kounali D, Vedi S, Compston JE, Beresford JN, Bhalla AK. Methotrexate in the treatment of rheumatoid arthritis. II. In vivo effects on bone mineral density. Rheumatology (Oxford) 2002;41:741-9.

8 Minaur NJ, Jefferiss C, Bhalla AK, Beresford JN. Methotrexate in the treatment of rheumatoid arthritis. I. In vitro effects on cells of the osteoblast lineage. Rheumatology (Oxford) 2002:41:735-40

\section{Authors' reply to Rozin and Quinn et al}

We read with interest the comments by Rozin and by Quinn and colleagues about our recent publication on low dose methotrexate (MTX) osteopathy in a patient with polyarticular juvenile idiopathic arthritis. Our report was not intended to suggest that MTX osteopathy may be more common than expected, and we agree that reported cases of low dose MTX osteopathy are exceedingly rare compared with the number of patients treated with MTX. Certainly, at a first glance it might not be very surprising that this patient developed serial insufficiency bone fractures after 25 years of prednisone treatment. However, the temporal association with the introduction of MTX and the multiplicity of fractures was striking.

We acknowledge that we did not provide further information about other possible factors that might have influenced the risk fracture in this patient. This 35 year old woman was not menopausal, did not smoke, and had a normal diet, and her physical activity was markedly restricted as her polyarticular joint involvement was severe. Unfortunately, family history of osteoporosis and bone mineral density were not assessed.

We disagree with Rozin about his interpretation of the technetium-99m diphosphonate bone survey. The multiple areas of increased uptake are asymmetric, which would be unlikely for a flare of polyarticular juvenile idiopathic arthritis. Moreover, the enhanced uptake which was localised to the femoral condyles and right calcaneum is not compatible with joint involvement. The increased uptake is certainly too marked and too diffuse to be related to multiple enthesopathies, which would also be very unusual clinical features in this type of inflammatory rheumatism. In a scintigraphic study of the cruciate deficiency model of knee arthritis in dog, the uptake ratio (unstable knee/contralateral knee) did not exceed 2.0 (controls value: 1.0 to 0.10 ). ${ }^{1}$ Conversely, in a semiquantitative ("scintimetric") ${ }^{99 \mathrm{~m}} \mathrm{Tc}$ diphosphonate scintigraphic follow up study of patients with peripheral fractures, the uptake ratio (fracture/normal reference site) was much higher (5.0 to 8.0). ${ }^{2}$ In our patient the uptake ratio was 5.5 and 3.7 for the left knee/right knee and right calcaneum/left calcaneum, respectively, which is further evidence for the diagnosis of multiple fractures.

Data for the in vitro effect of MTX on osteoblasts are conflicting, but we agree with Rozin and Quinn and colleagues that the in vivo effect assessed on bone mineral density is reassuring in most studies. ${ }^{3-6}$ Moreover, better control of the inflammatory arthritis should allow an increase of physical activity, which in turn may improve osteoporosis. The hypothesis of bone hypersensitivity or idiosyncrasy to MTX that is discussed by Rozin is only speculative, but appealing. Finally, we obviously concur with both comments and agree that such an exceptional observation of MTX osteopathy should certainly not deter from the use of MTX in idiopathic juvenile arthritis or other inflammatory arthritides when it is indicated.

\section{J Pouchot, M Rudler, S Gentelle, A Grasland, $P$ Vinceneux \\ Service de Médecine Interne, Hôpital Louis Mourier} Faculté Xavier Bichat, Paris VII, France

F Paycha

Médecine Nucléaire, Hôpital Louis Mourier, Faculté Xavier Bichat, Paris VII, France

Correspondence to: Dr J Pouchot, Service de Médecine Interne, Hôpital Lovis Mourier, 178, rue des Renouillers, 92700 Colombes, France; jacques.poucho+@Imr.ap-hop-paris.fr

\section{References}

1 Brandt KD, Schauwecker DS, Dansereau S, Meyer J, O'Connor B, Meyers SL. Bone scintigraphy in the canine cruciate deficiency model of osteoarthritis. Comparison of the unstable and contralateral knee. J Rheumatol 1997:24:140-5.

2 Spitz J, Laver I, Tittel K, Weigand H. Scintimetric evaluation of remodelling after bone fractures in man. J Nucl Med 1993;34:1403-9.

3 Uehara R, Suzuki Y, Ichikawa Y. Methotrexate (MTX) inhibits osteoblastic differentiation in vitro: possible mechanism of MTX osteopathy. J Rheumatol 2001;28:251-6.

4 Minaur NJ, Jefferiss C, Bhalla AK, Beresford JN. Methotrexate in the treatment of rheumatoid arthritis. I. In vitro effects on cells of the osteoblast lineage. Rheumatology (Oxford) 2002;41:735-40

5 Minaur NJ, Kounali D, Vedi S, Compston JE, Beresford JN, Bhalla AK. Methotrexate in the treatment of rheumatoid arthritis. II. In vivo effects on bone mineral density. Rheumatology (Oxford) 2002;41:741-9.

6 Buckley LM, Leib ES, Cartularo KS, Vacek PM, Cooper SM. Effects of low dose methotrexate on the bone mineral density of patients with rheumatoid arthritis. J Rheumatol 1997;24:1489-94.

\section{Clinical comparisons of RA between different populations: are they feasible?}

Rheumatoid arthritis (RA) is the most common chronic inflammatory disease, 
affecting about $1 \%$ of the white population, particularly female patients, and has considerable physical, psychological, and social repercussions.

In a paper published previously in the Annals, Dadoniene et al described and compared two cohorts of patients with RA from Vilnius (Lithuania) and Oslo (Norway). There were no significant differences in sex, age, extra-articular manifestations, education, or family history of RA between the groups. None the less, there were important differences in disease activity, disability, pain, emotional, mental and general health, with patients in the Vilnius group having the worst scores. The number of patients who had never used a disease modifying antirheumatic drug (DMARD) was similar in both groups. Vilnius patients had more commonly used azathioprine, sulfasalazine, and antimalarial drugs, whereas Oslo patients had used methotrexate, gold salts, cyclosporin, and D-penicillamine. Surgery was more common in the Oslo patients. That study was developed to compare the evolution and outcomes of two different populations with RA and was the first to include health related quality of life. The authors attributed the differences between these groups to differences in economic status, medical care, drugs used and, to a lesser extent, genetic differences.

During the past years the HLA system has been gaining an increasingly important role in the pathogenesis of autoimmune diseases. HLA polymorphism has multiple effects on the immune system.

HLA-DRBl alleles have been associated with RA in a number of populations. In the third hypervariable region of their DR $\beta 1$ chain, they share a sequence of amino acids named "the shared epitope" (SE). ${ }^{4}$

In a mestizo Colombian population we found that the SE ${ }^{70} \mathrm{QKRRA}^{74}$ in DRB1 ${ }^{*} 04$ alleles had the strongest association with RA. ${ }^{5}$ However, we did not find any significant association between HLA and RA in African Colombians, emphasising the importance of genetic differences even among populations living within the same country.

There have been different findings from one area to another. In Latin America, the differences are important. In Chilean patients the most common HLA-DRBl alleles were DRB $1{ }^{*} 0404$ and ${ }^{*} 0408$ and the SE influenced the radiographic evolution of hands erosions. ${ }^{78}$ In the Argentinian population the DRBI*0404 was also important but only $\mathrm{DRBI}^{*} 1001$ was related to RA severity. ${ }^{9}$ In the Peruvian population an association between RA and the SE was not found. ${ }^{10}$ There was a lack of uniformity in the development of these trials, but they all showed a lack of association between DRBI*0401 and RA in the Latin American population.

These findings suggest that SE inheritance and genetic influence may vary depending on the genetic background of the studied population even in apparently closely located countries. The previous study comparing the Norwegian and Lithuanian populations without inclusion of genetic typing may be misleading. Furthermore, not only may the HLA system play a part in the disease outcome and disease progression of these patients but pharmacogenetics may also be at least as important. The efficacy of methotrexate, sulfasalazine, and other DMARDs in reducing the radiological progression of RA erosions has been proved; however, their efficacy and tolerability may be influenced by mutations in their metabolic pathways or in their cellular targets. ${ }^{11} 12$

Epidemiology of autoimmune diseases is becoming more complex as our knowledge of HLA and genetics becomes more complete. The time is coming when diseases will be defined not only by their symptomatology but also by the genetic background of their hosts.

Corporación para Investigaciones Biológicas (CIB), Medellín, Colombia

J-M Anaya

School of Medicine, Universidad Pontificia Bolivariana, Medellín, Colombia

Correspondence to: $\mathrm{Dr} \mathrm{J}-\mathrm{M}$ Anaya, Unidad de Reumatología CIB, Cra. 72-A No 78-B-141, Medellín, Colombia; jmanaya@cib.org.co

\section{References}

1 Wolfe F, Pincus T. Rheumatoid arthritis: pathogenesis, assessment, outcome, and treatment. New York: Marcel Dekker, 1994

2 Dadoniene J, Uhlig T, Stropuviene S, Venalis A, Boonen A, Kvien TK. Disease activity and heath status in rheumatoid arthritis: a case-control comparison between Norway and Lithuania. Ann Rheum Dis 2003:62:231-5.

3 Klein J, Sato A. The HLA system - second of two parts. N Engl J Med 2000;343:782-6.

4 Gregersen PK, Silver J, Winchester RJ. The shared epitope hypothesis: an approach to understanding the molecular genetics of susceptibility to rheumatoid arthritis. Arthritis Rheum 1987;30:1205-13.

5 Anaya JM, Correa PA, Mantilla RD, ArcosBurgos $M$. Rheumatoid arthritis association in Colombian population is restricted to HLA DRB 1*04 QRRAA alleles. Genes Immunity 2002:3:56-8.

6 Anaya JM, Correa PA, Mantilla RD, Jimenez F, Kuffner T, McNicholl J. Rheumatoid arthritis in African Colombians from Quibdo. Semin Arthritis Rheum 2001;31:191-8.

7 Gonzalez A, Nicovani S, Massardo L, Aguirre V, Cervilla V, Lanchbury JS, et al. Influence of the HLA-DRB on susceptibility to and clinical expression of rheumatoid arthritis in Chilean patients. Ann Rheum Dis 1997:56:191-3.

8 Massardo L, Gareca N, Cartes A, Cervilla V, Gonzalez A, Jacobelli S. Possession of HLA-DRB correlates with erosive disease in Chilean patients with RA. Rheumatology (Oxford)

2002:41:153-6.

9 Citera G, Padulo LA, Fernandez G, Lazaro MA, Rossemfet MG, Maldonado JA. Influence of HLADR alleles on rheumatoid arthritis: susceptibility and severity in Argentine patients. J Rheumato 2001;28:1486-91.

10 Castro $F$, Acevedo E, Ciusani E, Angulo JM, Wollheim FA, Sandberg-Wollheim M. Tumor necrosis factor microsatellites and $\mathrm{HLA} A \mathrm{DRB} 1^{*}$, HLA-DQA $1^{*}$, and HLA-DQB1 * alleles in Peruvian patients with rheumatoid arthritis. Ann Rheum Dis $2001 ; 60: 791-5$

11 Ranganathan $\mathbf{P}$, Eisen S, Yokoyama WM, McLeod HL. Will pharmacogenetics allow better prediction of methotrexate toxicity and efficacy in patients with RA? Ann Rheum Dis 2003;62:4-9.

12 Taniguchi A, Urano W, Tanaka E, Afama $\mathrm{H}$ Yamanaka $\mathrm{H}$, Kamatani $\mathrm{N}$. Pharmacogenetics of disease modifiying anti-rheumatic drug [abstract]. Nippon Rinsho 2002;60:2339-44.

\section{Authors' reply}

We thank Drs Cadena and Anaya for their important and interesting comments on our paper reporting differences in disease activity and health status between matched patients in Norway and Lithuania.
Cadena and Anaya focus on the difference in the genetics of the HLA system or pharmacogenetic differences as a potential explanation for our findings. They refer to several studies, mainly from their own region of the world, where genetic markers have been associated with disease severity and progression. We agree that rheumatoid arthritis is associated with genes, mainly in the region encoding the major histocompatibility complex genes. ${ }^{2}$ However, the relative importance of genes is controversial also because low disease concordance has been found in studies of monozygotic twins. Some of the genetic studies indicate only a limited influence of genetic factors on disease susceptibility and progression, and this may suggest a relatively stronger importance of environmental factors.

However, we completely agree with the comments of the authors that genetic factors, ideally, should have been examined in both populations. However, blood samples were not available for such analyses, but our results would have been stronger if data on the genetic background of the populations had also been available.

T K Kvien, J Dadoniene

The Institute of Experimental and Clinical Medicine of Vilnius University Zygimantu -9, Vilnius, Lithuania LT2600; jolanta.dadoniene@ekmi.vu.It

\section{References}

1 Dadoniene J, Uhlig T, Stropuviene S, Venalis A, Boonen A, Kvien TK. Disease activity and health status in rheumatoid arthritis: a case-control comparison between Norway and Lithuania. Ann Rheum Dis 2003;62:231-5.

2 Jawaheer D, Gregersen PK. Rheumatoid arthritis. The genetic components. Rheum Dis Clin North Am 2002; 28:1-15.

3 Harney S, Wordsworth BP. Genetic epidemiology of rheumatoid arthritis. Tissue Antigens 2002;60:465-73

\section{FORTHCOMING EVENTS}

\section{American Back Society: Advanced Diagnosis and Treatment for Neck and Back Pain 2004}

13-15 November 2003; Las Vegas, Nevada 24 CME category I units

Tel: +1 5105369929

Fax: +1 5105361812

Email: info@americanbacksoc.org

Website: http://www.americanbacksoc.org

\section{Fourth International Symposium on Clinical and Economic Aspects of Osteoporosis and Osteoarthritis}

14-17 November 2003; Nice, France

Contact: Organisation Secretariat, YP Communication, 108 boulevard G Kleyer, $4000 \mathrm{Li}$ ge, Belgium

Tel: +32 (4) 2541225

Fax: +32 (4) 2541290

Email: yoland@piettecommunication.com

Website: http://nice.piettecommunication.com

\section{2nd International Forum on Geronto- Rheumatology}

27-29 November 2003; Amsterdam, The Netherlands 
Contact: Erna Kleinjan, project manager Mark Two Communications, PO Box 358, 3830 AK Leusden

Tel: + 31334345730

Fax: + 31334345720

Email: ekleinjan@marktwo.nl

Website: www.marktwo.nl

\section{International Congress on SLE and Related Conditions}

9-13 May 2004, New York, New York, USA Contact: The Oakley Group, 2014 Broadway, Suite 250, Nashville, Tennessee 37203, USA Tel: +l 6153222785

Fax: +1 6153222784

Email: Lupus2004@theoakleygroup.com

Website: http://www.lupus2004.org

\section{IOF World Congress on Osteoporosis}

14-18 May 2004; Rio de Janeiro, Brazil Abstract deadline 14 November 2003 IOF awards are available for scientists:

IOF Claus Christiansen Research Fellowship: 45000

IOF Servier Young Investigator Fellowship: 400000

Contact: Congress Secretariat at info@ osteofound.org

Website: www.osteofound.org

\section{International Society for the Study of the Lumbar Spine}

31 May-5 June 2004; Porto, Portugal Deadline for abstracts 15 November 2003 Contact: International Society for the Study of the Lumbar Spine, 2075 Bayview Avenue, Room MG 323, Toronto, Ontario, Canada M4N 3M5

Tel: 0014164804833

Fax: 0014164806055

Email: shirley.fitzgerald@sw.ca

\section{Xlth International Conference on Behçet's Disease}

27-31 October 2004; Antalya, Turkey Contact: Congress Secreteriat, Figur Congress and Organization Services Ltd. STI, Ayazmaderesi Cad. Karadut Sok. No: 7 80888 Dikilitas, Istanbul, Turkey

Tel: +90 (0212) 2586020

Fax: $+90(0212) 2586078$

Email: behcet2004@figur.net

Website: www.behcet2004.org

\section{4th International Congress on Autoimmunity}

3-7 November, 2004; Budapest, Hungary Deadline for receipt of abstracts: 20 June 2004

Contact: 4th International Congress on Autoimmunity, Kenes International-Global Congress Organisers and Association Management Services, 17 rue du Cendrier, PO Box 1726, CH-1211 Geneva 1, Switzerland Tel: +41 229080488

Fax: +41 227322850

Email: autoim04@kenes.com

Website: www.kenes.com/autoim2004

\section{Vlth European Lupus Meeting}

3-5 March 2005; Royal College of Physicians, London, UK

\section{CORRECTIONS}

Corrections printed in the journal also appear on the Annals website

www.annrheumdis.com

and are linked to the original publication.

Apoptosis of peripheral blood lymphocytes in patients with juvenile idiopathic arthritis (Smolewska E, Brozik H, Smolewski P, Biernacka-Zielinska M, Darzynkiewicz Z, Stanczyk J. Ann Rheum Dis 2003;62:761-3.)

In fig 1 of this article the numbers of patients were corrected but the size of
Contact: Julia Kermode, Conference organiser of the British Society of Rheumatology Email: Julia@Rheumatology.org.uk

\section{Future EULAR congresses}

9-12 June 2004; EULAR 2004; Berlin, Germany

8-11 June 2005; EULAR 2005; Vienna, Austria

21-24 June 2006; EULAR 2006; Amsterdam, The Netherlands

\section{Future ACR meetings}

24-28 October 2003; 67th Annual Scientific Meeting; Orlando, Florida

16-21 October 2004; 68th Annual Scientific Meeting; San Antonio, Texas

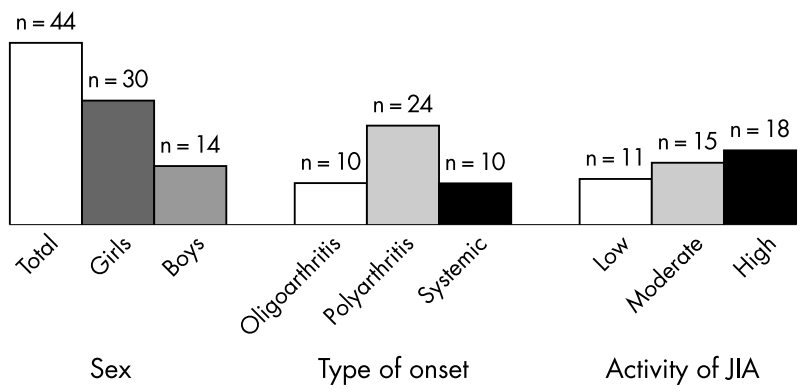

Figure 1 Clinical characteristics of children with JIA.

Cyclosporin A monotherapy versus cyclosporin $\mathrm{A}$ and methotrexate combination therapy in patients with early rheumatoid arthritis: a double blind randomised placebo controlled trial (Gerards A H, Landewé R B M, Prins A P A, Bruijn G A W, Goei Thè H S, Laan R F J M, Dijkmans B A C. Ann Rheum Dis 2003;62:291-6.)

One of the authors names was supplied incorrectly. The correct authors are as follows: Gerards A H, Landewé R B M, Prins A P A, Bruyn G A W, Goei Thè H S, Laan R F J M, Dijkmans B A C.

the boxes was not corrected at the same time. The correct figure is shown below. 